\title{
ORIGINAL ARTICLE \\ CLINICAL PROFILE OF PAEDIATRIC PHARYNGO-OESOPHAGEAL FOREIGN BODIES IN A TERTIARY HEALTH INSTITUTION, NORTH WEST NIGERIA.
}

\author{
Aliyu D, Iseh KR, Abdullahi M, Amutta SB. \\ Department of Ear, Nose and Throat \\ Usmanu DanFodiyo University Teaching Hospital Sokoto.
}

\begin{abstract}
Background: Pharyngo-oesophageal foreign bodies (PFB) in children are frequent clinical entity requiring an urgent radiological and endoscopic surgical intervention to avert life threatened complications seen in otorhinolaryngology practice.
\end{abstract}

Objective: The objective of this study is to describe the pattern of pharyngooesophageal foreign bodies' impaction, management challenges and the need for health education to care givers.

Method: A retrospective review of all cases of paediatric patients with suspected or confirmed history of PFB from January 2007 to December 2011.

The information retrieved included the biodata, types of foreign body, clinical and radiological findings, treatment and outcome.Results were analysed by simple statistical table.

Results: Sixty seven patients diagnosed with Pharyngo-oesophageal Foreign Body, forty three (64\%) were males while 24(36\%) were females with $M: F$ ratio $=1.8: 1$ and Mean age of 4.9 years (age range 6 months to 13years.).Coins 36(54\%) were the commonest PFB. Only 13(19\%) presented to hospital within 24hours of ingestion. Common presenting symptom were Vomiting $70 \%$, and dysphagia in 73\%. Fifty four (81\%) had positive history of FB ingestion and 13(19\%) of the patient PFB were detected radiologically. Sixty three (94\%) had rigid oesophagoscopy and removal under general anaesthesia while 4(6\%) fish bone FB in the tonsils were extracted in the out-patient clinic after xylocaine spray. Post operative complications were noticed in 13(19\%).

Conclusion: Coin is the commonest pharyngoesophageal foreign body in children. Only 19\% of these patient presented to hospital within 24hours therefore public health education to parents and care givers is recommended.

Key words: foreign bodies, pharyngo-oesophageal, paediatric

\section{Introduction}

Impaction of ingested foreign body (FB) in the aerodigestive tract is a common emergency in the otorhinolaryngology practice ${ }^{1,2}$. In the paediatric age group, Children who areless than five years of age are particularly susceptible because of their inquisitive nature, tendency to explore their surroundings and putting objects in to their mouth more frequently ${ }^{3,4}$. Different objects

Correspondence: Dr Aliyu DJ

Department of ENT, Usmanu Danfodiyo

University Teaching Hospital, Sokoto.

E-mailall4dan5@yahoo.com.

Caliphate Medical Journal ingested ranges from liquids like acids, bases, petroleum products and solids like coins,toys,pins, plastics.The impaction of these foreign bodiesresults in dramatic presentation of drooling or dysphagia which may be a source of apprehension among the care giver and the healthcare providers ${ }^{3}$

When ingested, this could spontaneously move down the oesophagusand expelled through the lower gastrointestinal tract or get impacted thereby requiring emergency oesophagoscopy or lateral pharyngotomyfor its removal.5, 6 
Serious and sometimes fatal complications associated with impacted pharyngooesophageal foreign objects due either to late diagnosis, late referrals to the hospital or mismanagement have been reported. ${ }^{1-8}$

A high index of suspicion of the possibility of FB is required in pediatric patient who have persistent vomiting, dysphagia and cough. They should be evaluated thoroughly radiologically and sometimes endoscopically ${ }^{3}$. The aim of this study is tohighlighten management challenges posed by impacted PFB in Usmanu Danfodiyo University Teaching Hospital, North West of Nigeria with a view of having an up to date functional paediatric endoscopic facilities and public health education to parents and care givers to keep the most vulnerable children under surveillance at all times.

\section{Methodology}

This is a retrospective study of clinical records of all pediatric patients who presented at first visit to the otorhinolaryngology department of Usmanu Danfodiyo University Teaching Hospital Sokoto over a five-year period between January 2007 and December 2011 with a history or suspected history of Pharyngoesophageal foreign body impaction. The clinical records of the patients with PFB were analysed for age, sex, history of sudden vomiting, dysphagia, drooling of saliva, radiological investigation, treatment and outcome. The data was analyzed using simple tables and figures. All the patients had plain X-rays of the soft tissue neck and chest. Were plain X-rays was not helpful in few of them, a contrast study was ordered. Rigid pharyngo-oesophagoscopy and removal under general anaesthesia was carried out within 48hours of presentation at the hospital while those with fish bone foreign body impacted in the tonsils had it removed under direct vision in the outpatient clinic after Xylocaine spray. Those with longstanding impaction had nasogastric tube passed endoscopically with longer duration of hospital stay.
All patients had postoperative parenteral antibiotics therapy for 48hrs and continued with oral. Majority were discharged home two to three days after removal except few who developed complications that stayed for about two weeks.

Excluded from this study were cases confirmed radiologically and or endoscopically to be laryngo-tracheobronchial foreign bodies and adults with foreign body ingestion.

From all revised papers, datas regarding children age and sex, FB type, location, most frequent symptom and complication, and delay at diagnosis, were drawn and compared with our experience.

\section{Results}

A total number of 487 peadiatric patients with ear, nose and throat foreign bodies were seen during the study period, 67(13.8\%) patients had pharyngooesophageal foreign body ingestion. There were 43(64\%) males and $24(36 \%)$ females with male to female ratio of $1.8: 1$ and a mean age of 4.9years (range 6months - 13years.). Children aged group 0-5 years were the most affected (78\%), while 6-10 years accounted for 19\% as seen in table I. While in table II, Coins $36(54 \%)$ were the commonest followed by plastics $10(15 \%)$, safety pins and needles $8(12 \%)$, ear rings $5(7 \%)$, fish bones $4(6 \%)$,

Table I: Age of Patient with Foreign Body

\begin{tabular}{lcc}
\hline Age in year's & $\begin{array}{c}\text { Number } \\
\text { of patient }\end{array}$ & $\begin{array}{c}\text { Frequency } \\
\text { (\%) }\end{array}$ \\
\hline $0-5$ & 52 & 78 \\
$6-10$ & 13 & 19 \\
$>11$ & 2 & 3 \\
Total & 67 & 100 \\
\hline
\end{tabular}


Table II: Types of and Frequency of Foreign Body (FB)

\begin{tabular}{lrc}
\hline Nature of FB & Number & $\begin{array}{c}\text { Frequency } \\
\text { (\%) }\end{array}$ \\
\hline Coins & 36 & 54 \\
Plastics & 10 & 15 \\
Pins and needles & 8 & 12 \\
Ear rings & 5 & 7 \\
Fish bones & 4 & 6 \\
Metallic tap knob & 2 & 3 \\
Button disc battery & 2 & 3 \\
Total & 67 & 100 \\
\hline
\end{tabular}

metallic tap head 2(3\%), button battery $2(3 \%)$. The duration of impaction ranged from few hours to five years. Few children 13 (19\%) presented within 24hours, 30 (45\%) between one day and thirty days, while 20 (30\%) between 1 and 12months (table III). The most frequent presenting symptom was vomiting 29(43\%) followed by Dysphagia $20(30 \%)$, drooling of saliva $10(15 \%)$ while $8(12 \%)$ had no symptoms. Only 54(81\%) patients had positive history of foreign body impaction and in 13(19\%) of patients it was detected radiologically. Rigidoesophagoscopy under general anaesthesia were carried out in $63(94 \%)$ while 4(6\%) had foreign body extracted under direct vision after xylocaine spray at the outpatient clinic. Post operative complications noticed were hyperaemia and oedema $6 \%$, bruises and bleeding $7 \%$, with short segment oesophageal stricture in 6\% patient after six months of follow up. No mortality was recorded in this study.

Table III: Time Elapsed before Presentation to Hospital.

\begin{tabular}{lcc}
\hline Duration & $\begin{array}{c}\text { Number of } \\
\text { patients }\end{array}$ & $\begin{array}{c}\text { Frequency } \\
\text { (\%) }\end{array}$ \\
\hline 0-6hrs & 5 & 7 \\
- -24hrs & 8 & 12 \\
- 7days & 8 & 12 \\
- 4weeks & 22 & 33 \\
- 52weeks & 20 & 30 \\
>52weeks & 4 & 6 \\
Total & 67 & 100 \\
\hline
\end{tabular}

\section{Discussion}

Foreign body in the aero digestive tract is a frequent occurrence in children especially in their first six years of life, with a peak in children older than 3years. ${ }^{1,3-9}$. In the present study, the majority of cases involved children less than 5 years (78\%) as in Table I, showing similarities with studies on this subject all over the world. ${ }^{3-6,10}$ Males are commonly affected than females this can be associated with high levels of inquisitiveness among the male children. Children less than 3 years of age have a high propensity for placing objects in their mouths which is referred to as oral exploration. Increase mobility and the introduction of adult food, incomplete dentition and immature swallowing coordination add to the risk of foreign body ingestion ${ }^{1}$. Various studies reported the most frequent foreign bodies results in metal objects such as batteries and coins, plastics, fish bones and broken tooth fragments ${ }^{3-7}$. In Table II, Coins were by far the most frequent

foreign bodies ingested, followed by plastics and needles which is in agreement with the work done here in south east and western part of Nigeria.7,11,12 This was different from the reports in Asian literatures were bones were found in high frequency. ${ }^{10}$ These stressed the importance of public health education to parents and care givers, especially with regards to conducive play environment devoid of coins or easily ingestible objects.

Most of our patients (31\%) presents within the first seven days of symptoms while $30 \%$ of the patients that presented between 1 and 12 months were as a result of ignorance in seeking help from traditional herbalist with a believe that the foreign body can be removed especially when access to medical facility is not onsite, coupled with their poor socioeconomic status as showed in Table III. And these explain the complications in 19\% observed in this study as those that presented early had no attendant complication. Other complications associated with retained 
pharyngo-esophageal foreign bodies are tracheal compression and erosion through the mucosa, with foreign body's migration into adjacent structures, such as the respiratory tract or the aorta, haematemesis, mediastinitis, pneumothorax, pleural effusion, tracheoesophagia fistula, septicemia, pneumonia, aspiration and sometimes death could result .8, 11, 12, 17

In this study about one quarter of the patient's symptom were noticed by the observant parents when the object that the child was playing with could not be located around the child, which suggested an option of swallow. Self reporting was also noticed among the older, fully conscious,

communicative children who may still be able to localize the point or position of the swallowed coin however this is often not reliable ${ }^{18}$. In many instances the ingestion goes unrecognized or unreported until the onset of symptoms, which may be remote from the time of ingestion ${ }^{10}$. The commonest symptom reported by most of our patients or caregiver was drooling of saliva, chest pain and dysphagia. The anatomic proximity of the upper airway and oesophagus permit the development of respiratory symptoms like cough and stridor as observed in our study ${ }^{19}$. Young children and the mentally impaired may present with choking, refusal to eat, vomiting, drooling, wheezing, bloodstained saliva, or respiratory distress..$^{20}$ These should also suggest foreign body ingestion in this group of children thus the need to further evaluate them.

All our diagnosis was supported with plain radiograph not only to make diagnosis but also to localize the radio-opaque foreign body, for medico legal reason, and follow up of patients. In $79 \%$ of our patients foreign body was detected radiologically and the remaining had positive history of foreign body ingestion. Even though contrast studies was carried out in two of our patients with long standing ingestion in the thoracic oesophagus, a contrast examination should not be performed routinely because of the risk of aspiration and because coating of the foreign body and esophageal mucosa compromises subsequent endoscopy ${ }^{21,22}$.

Management of the patient is influenced by the patient's age and clinical condition; the size, shape, position of the foreign body if vertical or horizontal and classification of the ingested material; the interval between

impaction and removal; appropriate functional available instruments and the technical abilities of the endoscopist are the numerous challenges that has to be surmounted to achieve excellent results ${ }^{2-14}$.

Despite the risk associated with the aerodigestive foreign bodies attempted removal with various methods such as induction of vomiting, finger insertion into the child's oropharynx was noted in more than one third of the patients in this study. This further emphasizes the need of public health education to both parents and care givers ${ }^{23}$.

In this study, $94 \%$ of our patients had their foreign bodies removed using an appropriate sized rigid oesophagoscope under general anaesthesia and with minimal complication and $2(3 \%)$ could not be located which was subsequently passed out through the lower gastrointestinal tract. While fish bones lodged in the tonsils in $6 \%$ of our patient mostly older children were removed as an outpatient clinic procedure following xylocainespray. None of our patient underwent Lateral Pharyngotomy or thoracotomy. It is also advised to have a second look after removal of foreign body to exclude the possibility of a second foreign body or assessing the degree of injury at point of impaction in long standing foreign body impaction. Majority of our patient had a nasogastric feeding tube passed endoscopically in patient with longstanding 
impaction and those who had mucosal injury during the rigid oesophagoscopy. There was no death reported from our study similar to findings elsewhere. ${ }^{10-17}$ In conclusion, pharynxgoesophageal foreign body impaction is the commonest indication for emergency rigid oesophagoscopy. In this study, coins was the commonest foreign body found in the upper gastrointestinal tract. It is therefore of paramount importance that a functional up to date endoscopic unit backed by skilled manpower be made easily accessible to all Nigerians. The presence of a foreign body is naturally distressing; it is better to teach how to prevent such eventuality. Therefore public awareness through schools, media, local community leaders and health professionals is recommended.

\section{References}

1. Simon C, Nimesh P, Ray C. foreign bodies in the aerodigestive tract in children. In: Micheal G, Ray C (eds). Scott-Brown's otorhinolaryngology, Head and Neck Surgery-Paediatric otorhinolaryngology. $7^{\text {th }}$ Ed. Hodder Arnold 2008; 1184-1188.

2. Ngo A, Sim TP. Otorhinolaryngeal foreign bodies in children presenting to the emergency department. Singapore Med J. $2005 ; 46: 172-8$.

3. Little DC, Shah SR, St Peter SD et al., oesophageal foreign bodies in the pediatric population: our first 500 cases, Journal of Pediatric Surgery. 2006; 41(5): 914-918.

4. Higo R, Matsumoto $Y$, Ichimura K, and Kaga K. Foreign bodies in the aerodigestive tract in pediatric patients, Auris Nasus Larynx. 2003; 30(4): 397-401

5. Weissberg D. and Refaely Y. Foreign bodies in the oesophagus, Annals of Thoracic Surgery, 2007; 84(6): 1854 1857.

6. Mahafza T, Batieha A, Suboh M and Khrais T. Esophageal foreign bodies: a Jordanian experience. International Journal of
Pediatric Otorhinolaryngology, 2002; 64(3) : $225-227$.

7. Iseh KR, Oyedepo $\mathrm{OB}$ and Aliyu D. Pharyngo-oesophageal Foreign Bodies: Implications for Health Care Services in Nigeria. Annals of African Medicine 2006; 5: 52-55.

8. Obiako MN. Tracheoesophageal fistula. A complication of foreign body. Ann OtolRhinol Laryngol 1982: 91:325-329.

9. Lewis S. Diseases of the oesophagus. In: Micheal G, Ray C ( eds). Scott-Browns otorhinolaryngology, Head and Neck Surgery- Peadiatric otorhinolaryngology. Seventh edition. Hodder Arnold 2008; 1282-1292.

10. Li ZS, Sun ZX, Zou DW, Xu GM, Wu RP, Liao Z. Endoscopic management of foreign bodies in the upper-GI tract: experience with 1088 cases in China. Gastrointestinal Endoscopy 2006; 64(4): 485 - 492.

11. Okafor BC. Foreign bodies in the pharynx and oesophagus. Nigerian Medical Journal 1979; 9:321-325.

12. Okeowo PA. Foreign bodies in pharynx and oesophagus - a ten year review of patients seen in Lagos. Nigerian Quarterly Journal of Hospital Medicine 1985; 3:4650 .

13. Waltzman ML. Management of esophageal coins. Current Opinion in Pediatrics 2006; 18(5): $571-574$.

14. Hachimi-Idrissi S, Corne L, Vandenplas Y. Management of ingested foreign bodies in childhood: our experience and review of the literature. Eur J Emerg Med 1998; 5:319-23.

15. Maroof A K, Azhar H, Abdul J C. Management of foreign bodies in the esophagus. J Coll Physicians Surg Pak Apr 2004; 14(4): 218-20. 
16. Tokar B, Cevik AA, Ihan H. Ingested gastrointestinal foreign bodies: predisposing factors for complications in children having surgical or endoscopic removal. Pediatric Surgery International 2007; 23(2): 135 - 139.

17. Hammond P, Jaffray B, Hamilton L. Tracheoesophageal fistula secondary to disk battery ingestion: a case report of gastric interposition and tracheal patch. $J$ Pediatr Surg. 2007; 42(7): E39-E41.

18. Connolly AA, Birchall M, Walsh-Waring GP, Moore-Gillon V. Ingested foreign bodies: patient guided localization is a useful clinical tool. Clin Otolaryngol 1992; 17:520-4.

19. Louie MC, Bradl S. Foreign body ingestion and aspiration, Pediatrics in Review2009; 30(8): 295-301.
20. Kamal I, Thompson J and Paquette DM. The hazards of vinyl glove ingestion in the mentally retarded patient with pica: new implications for surgical management. Can J Surg 1999; 42:201-204.

21. Okoye IJ, Imo AO and Okwulehie V. Radiologic management of impacted coin in the oesophagus--a case report. Niger J Clin Pract. 2005;8(9):56-59.

22. Cerri RW and Liacouras CA. Evaluation and management of foreign bodies in the upper gastrointestinal tract, Pediatric Case Reviews, 2003; 3(3): 150- 156.

23. Gregori D. Preventing foreign body injuries in children: a key role to play for the injury community. Injury Prevention 2008;14(6): 411. 